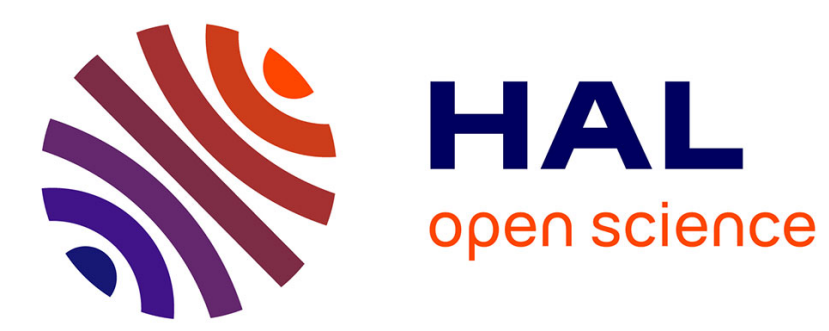

\title{
HOT ELECTRON EMISSION FROM SILICON UNDER PULSED LASER EXCITATION
}

\author{
M. Bensoussan, J. Moison
}

\section{To cite this version:}

M. Bensoussan, J. Moison. HOT ELECTRON EMISSION FROM SILICON UNDER PULSED LASER EXCITATION. Journal de Physique Colloques, 1981, 42 (C7), pp.C7-149-C7-153. 10.1051/jphyscol:1981717 . jpa-00221653

\section{HAL Id: jpa-00221653 https://hal.science/jpa-00221653}

Submitted on 1 Jan 1981

HAL is a multi-disciplinary open access archive for the deposit and dissemination of scientific research documents, whether they are published or not. The documents may come from teaching and research institutions in France or abroad, or from public or private research centers.
L'archive ouverte pluridisciplinaire HAL, est destinée au dépôt et à la diffusion de documents scientifiques de niveau recherche, publiés ou non, émanant des établissements d'enseignement et de recherche français ou étrangers, des laboratoires publics ou privés. 
M. Bensoussan and J.M. Moison

Centre National d'Etudes des Tézécommunications, Département OMT/PMS, 196 rue de Paris, 92220 Bagneux, France

Résumé : - Sous excitation modérée par un laser à impuissions, le silicium emet des èlectrons dans le vide à des énergies de photon bien en dessous du travai1 de sortie $\Phi$. Deux processus distincts sont observēs : 1) une photoémission à deux quanta à de faibles flux de photon et à de fortes énergies de photon $(>\Phi / 2)$ et 2$)$ une thermoémission à de forts flux de photon ou de faibles énergies de photon $(<\Phi / 2)$. Alors que le premier effet donne des informations sur les propriêtés de structures de bande électronique du silicium sous excitation, le second sonde les propriétés du plasma de porteurs photogénérés. La températurę de ce plasma est évaluēe à $(1800 \pm 100) \mathrm{K}$ pour une irradiance de $\left(0.04 \mathrm{Jcm}^{-2}, 2 \mathrm{~ns}\right)$.

Abstract : - Under moderate pulsed laser excitation, silicon is shown to emit electrons in the vacuum at photon energies well below the work function $\Phi$. Two distinct processes are observed, 1) a two-quantum photoemission at low photon fluxes and high photon energies $(>\Phi / 2)$ and, 2) a thermoemission at high photon fluxes or low photon energies $(<\Phi / 2)$. While the first effect yields information about the electronic structure of silicon under irradiation, the second one probes the properties of the carrier plasma. The temperature of this plasma has been evaluated to $(1800 \pm 100) \mathrm{K}$ for $\left(0.04 \mathrm{Jcm}^{-2}, 2 \mathrm{~ns}\right)$ irradiances.

1. Introduction - In the past few years, the behavior of semiconductors under intense pulsêd laser excitation has attracted a great deal of attention, and several anomalous effects have been attributed to the high carrier densities involved ( 1 ). The interest for such topics has been renewed and focused by the controversy on puised laser annealing of silicon (2). It is usually agreed anyhow, that the formation of a hot electron-hole plasma precedes and initiates the observed effects. If thermalization of this plasma takes place, many electrons are likely to be driven high in the conduction band, and a number of them higher than the vacuum level. An electron emission should then be observed, even when the excitation photon energy is lower than the surface barrier potential $\Phi$. A study of these electrons (overall yields, angutar distribution, energy distribution) must yield information about the "heating" mechanisms. Up to now, most experiments of this kind have been carried out on metals (3-6). We report here the preliminary results of such a study on crystalline silicon.

2. Experimental set-up/results : - The experimental set-up has been described elsewhere (7). The sample is a (111) n-doped silicon wafer, cleaned and annealed under ultra-high vacuum to obtain a (7x7) surface structure, as checked by LEED/Auger measurements. Optical excitation is performed with a pulsed dye laser (pulse duration $=2 \mathrm{~ns}$, rep. rate $=20 \mathrm{~Hz}$ ). The characteristics of the beam impact on the sample, 
i.e. energy, spatial and temporal energy distribution, are carefully monitored and a peak photon flux Jph is deduced. Photoemitted electrons are collected in a vacuum diode set-up. The photocurrent pulse is monitored on a fast-rise oscilloscope and integrated in an amplifier giving the charge/pulse $Q$.

At photon energies between $\Phi / 2$ and $\Phi$, two distinct behaviors are observed. At low photon fluxes (Jph $<5 \times 10^{25} \mathrm{~cm}^{-2} \mathrm{~s}^{-1}$ ), the photocharge/pulse $Q$ is proportionnal to the square of the laser energy and to the reciprocal of the impact area. The relation between Jph and the electron flux Je is then :

$$
\mathrm{Je}=\mathrm{B}(\mathrm{Eph}) \mathrm{Jph}^{2}
$$

This relation implies that the photocharge current pulse duration is shorter than the laser pulse duration by about 1.4 , which has been checked at high photon energy and high flux. Then the relation is clearly demonstrated over several orders of magnitude (7) between $\Phi / 2=2.3 \mathrm{eV}(8)$ and $3.7 \mathrm{eV}$. The $B($ Eph) spectrum has been deduced (9) . B is an increasing function of Eph and falls to zero below $\Phi / 2$.

on the other hand, at higher photon fluxes, Q increases much more rapidely with Jph. Again, the photocurrent pulse duration could be measured only at high values, and was found to be about equal to the laser pulse duration. For comparison purposes, Je values were calculated with the assumption that it is true for lower photon fluxes. The Je vs Jph curve is plotted in figure 1.

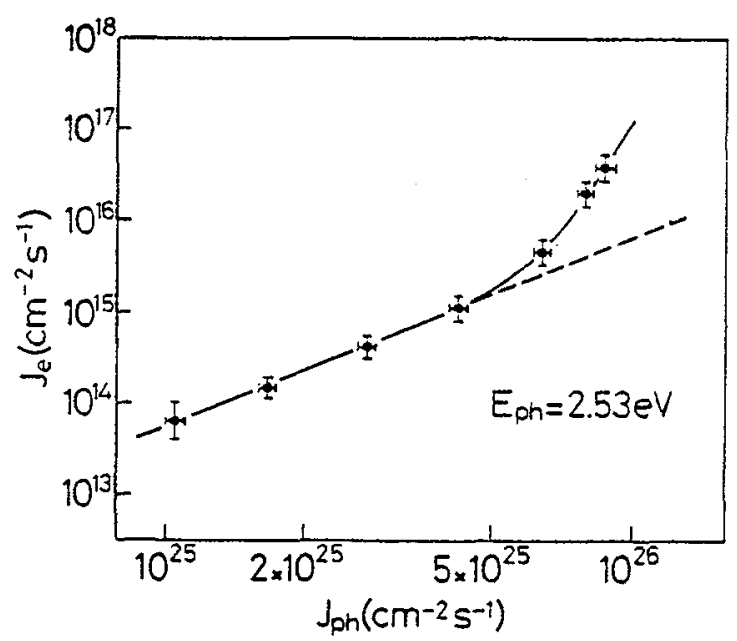

Fig. 1 : Electron flux Je vs photon flux Jph.

The transition between the two behaviors takes place at photon fluxes of $(7 \pm 2) \times 20^{25} \mathrm{~cm}^{-2} \mathrm{~s}^{-1}$ for photon energies ranging from $2.3 \mathrm{eV}$ to $3.7 \mathrm{eV}$. Below $\Phi / 2, \mathrm{~B}$ is zero and only the second behavior is observed from low photon fluxes upwards. It is shown in figure 2 for photon fluxes below $8 \times 10^{25} \mathrm{~cm}^{-2} \mathrm{~s}^{-1}$ i.e. the range where the first behavior is dominant above $\Phi / 2$.

3. Discussion : - The basic photon-semiconductor interaction for Eph > Eg is the electron-hole pair creation. Obviously, for Eph $<\Phi$ this mechanism cannot account for electron emission above the vacuum level. The processes by which the photon energy is 


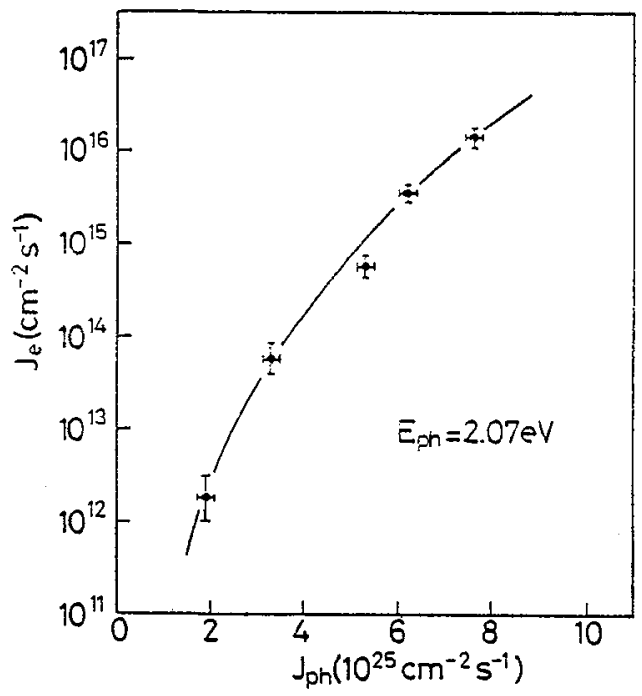

Fig. 2 : Electron flux Je vs photon fTux Jph.

further increased are not well established. They become active only at high injection levels, near the optical damage limit or the laser annealing level, which leads to spurious effects. Indeed, most authors switched to picosecond excitation in order to avoid "thermal effects" (4). Actually, it seems that, in the nanosecond range, several processes can be observed. It may be noted, before any discussion of our results, that a 11 our measurements were reversible and that no visible degradation of the sample was observed, in agreement with the clässical value of the annealing level (1 $\mathrm{Jcm}^{-2}$ for a $15 \mathrm{~ns}, 0.53 \mu$ laser pulsje (10), when our top values are about $0.07 \mathrm{Jcm}$ ).

Our experiments clearly show that, at moderate irradiance levels (Jph $<5 \times 10^{25} \mathrm{~cm}^{-2} \mathrm{~s}^{-1}$ ) and photon energies above $\Phi / 2$, two-quantum photoemission is the dominant process. We suggested two mechanisms accounting for it, 1) two-photon absorption with either real or virtual transitions (genuine two-photon absorption or cascade of one-photon absorptions) and, 2) non-radiative Auger recombination (7). At higher irradiation levels, or at photon energies below $\Phi / 2$ where two-quantum photoemission is impossible, another mechanism become much more effective. Similar behaviors have already been observed on metals (3). Owing to their occurence at low photon energy and their very fast increase with irradiance, they have usually been attributed to thermoemission, i.e. emission of the electrons heated above the vacuum level by thermalization of the carrier plasma, or of the whole crystal. We shall examine the results of figure 2 under this assumption.

It is usually admitted that thermalization inside the carrier plasma takes place in the picosecond range by carrier-carrier interactions as Auger recombination and impact ionization (11). Thermalization of the carrier plasma with the lattice is pro- 
bably very much slower, although the subject is still a matter of discussion. Anyhow, as we are interested in the electron gas for thermionic calculation purposes, we can assume that, within the laser pulse, the electron gas is in constant thermal equilibrium. Then its temperature Te can be defined and deduced from Je by use of the Richardson equation (12): $\left(\mathrm{Je} \mathrm{cm}^{-2} \mathrm{~s}^{-1}\right)=10^{29}(\mathrm{kTe})^{2} \exp (-\mathrm{a} / \mathrm{kTe})$, where kTe is expressed in $\mathrm{eV}$ and where $\Phi_{\mathrm{a}}$ is the actual work function. From the value of the two-quantum photoemission threshold $(\Phi / 2 \pm 0.1 \mathrm{eV})$, obtained at the irradiance levels that we are now considering, we infer that the surface barrier is not much altered and $\Phi \mathrm{a}=4.6 \pm 0.2 \mathrm{eV}$. To deduce the true values of je from $Q$ measurements, the photocurrent pulse duration should be measured, even at low photon fluxes. This is unfortunately impossible with the low currents involved. The assumption that this duration is, on the whole range of photon flux, equal to the laser pulse duration is doubtful. Indeed, considering the fast increase of $Q$ with $\mathrm{Jph}$, one would expect a rather shorter photocurrent pulse duration, by a factor 3 . The lengthening of the thermoemission duration can be related to observations performed at very high irradiation levels showing that the laser pulse effects linger nanoseconds after its end (13). In view of these remarks, the lower Je values of figure 2 may be underestimated by a factor 3 . The electron temperatures deduced from them by use of the Richardson equation with $\Phi_{a}=4.6 \mathrm{eV}$ are plotted as a function of Jph in figure 3 . The incertitude on these temperatures resulting from the above discussion of $\Phi \mathrm{a}$ and $\mathrm{Je}$, is about $\pm 100 \mathrm{~K}$. In view of the high temperatures obtained $(1600 / 2000 \mathrm{~K})$ and

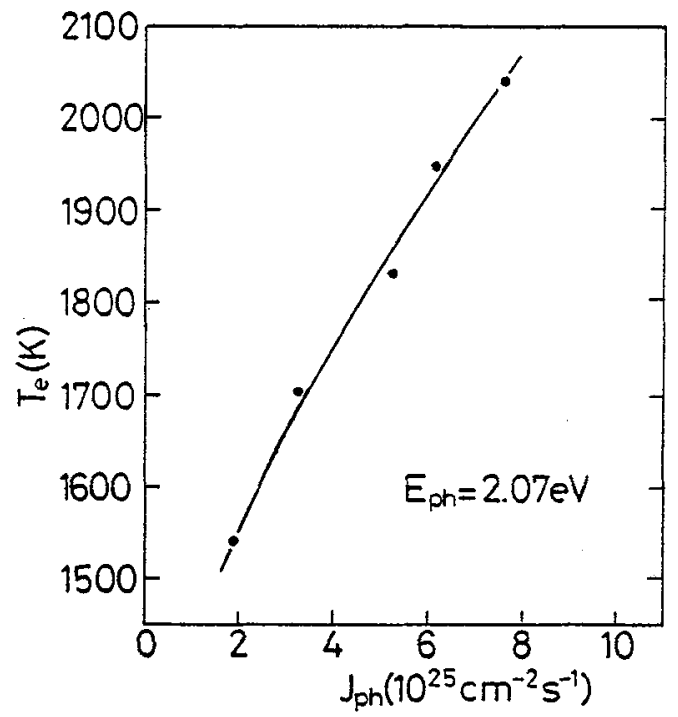

Fig. 3 : Electron temperature Te vs photon flux Je.

of the moderate irradiation lejvels considered, it is clear that thermalization of the carrier plasma with the lattice is not achieved during thermoemission and, when achieved, leads to a peak lattice temperature well below the melting point. A rough estimate of the specific heat involved in the electron gas can be made by the relation $c=\alpha t_{L}(\mathrm{dJph} / \mathrm{dTe})$, where $t_{L}$ is the laser pulse duration and $\alpha$ the absorption 
coefficient. Taking into account the possible increase of the absorption coefficient under high irradiation (13), we find $0.008<\mathrm{c}\left(\mathrm{Jcm}^{-3} \mathrm{~K}^{-1}\right)<0.6$. If a mere heat exchange between carrier plasma and lattice took place, the palsmon energy remaining low (11), the peak bulk temperature would range between $5 \mathrm{~K}$ and $500 \mathrm{~K}$, the upper boundary value being probably overestimated. This fact, together with the rather short photocurrent pulse length, induces us to believe that our experiments refer to the properties of the "primary" carrier plasma obtained at moderate irradiance levels. The mechanisms considered here, which are the precursors and possibly the initiators of pulsed laser annealing are under further study by now in our laboratory:

References

(1) W.B. Gauster and J.C. Bushe1T, J. App T. Phys. 41, 3850 (1970)

Y.S. Lin and K.L. Wang, App1. Phys. Lett. 34, 363 (1979).

D.H. Auston et a1., App1. Phys. Lett. 33, 437 (1978).

(2) D.H. Auston et al., in "Laser-Solid Interaction and Laser Processing"

(Am. Inst, of Physics, New York 1979).

J.A. Van Vechten, R. Tsu, W. Saris, D. Hoonhout, Phys. Lett. 74A, 417 (1979)

(3) E.M. Logothetis and P.L. Hartman, Phys. Rev. 187, 460 (1969).

(4) J.H. Bechtel, W.L. Smith, N. Bloembergen, Phys. Rev. B15, 4557 (1977).

(5) R. Yen, P. Liu, M. Dagenais, N. Bloembergen, Opt. Comm. 31, 334 (1979).

(6) P.P. Barashev, Phys. Stat. Solidi (a) 9,9 (1972).

(7) M: Bensoussan, J.M. Moison, B. Stoesz, C. Sëbenne, Phys. Rev. B23, 992

(8) C. Sébenne, Bolmont, Guichar, Balkanski, Phys, Rev. B12, 3280 (1975).

(9) J.M. Moison, M. Bensoussan, Solid State Comm., on press.

(10) R.F. Wood, and G.E. Giles, Phys. Rev. B23, 2923 (1981).

(11) E.J. Yoffa, Phys. Rev. B21, 2415 (1980).

(12) See for instance E. Spenke "Electronic Semiconductors" (1958).

(13) A. Aydin 1, H.W. Lo, M.C. Lee and A. Compaan, Phys. Rev. Lett. 46, 1640 (1981). 